\title{
Clinical Studies of Dental Cements: IV. A Preliminary Study of a Zinc Oxide-Eugenol Cement for Final Cementation
}

\author{
T. D. GILSON and G. E. MYERS \\ School of Dentistry, University of Michigan, Ann Arbor, Michigan 48104
}

An experimental reinforced zinc oxideeugenol cement of compressive strength 8,000 to $9,200 \mathrm{psi}(562$ to $647 \mathrm{~kg} / \mathrm{sq} \mathrm{cm})$ was studied clinically for the final cementation of all types of inlays, crowns, and bridges. Patients were recalled and their teeth were examined for loose restorations and symptoms of leakage. Success rates of $94.4 \%$ for single restorations and $93.6 \%$ for bridge retainers justify further clinical use of the cement.

The problems associated with the cementation of dental restorations with zinc phosphate cement were outlined in a previous paper. ${ }^{1}$ A means of alleviating these problems by the interim cementation of restorations with a zinc oxide-eugenol cement was discussed. Because these cements must allow subsequent removal of the restoration before final cementation with a zinc phosphate cement, there is the ever-present danger of a restoration becoming loose and leaking without the patient's knowledge, a situation which is usually accompanied by rapid caries of the abutment tooth. Numerous attempts have been made in recent years to produce a fortified zinc oxide-eugenol cement that would be strong enough for use as a final cement, and eliminate the period of interim cementation.

Although zinc oxide-eugenol cements have been produced with a compressive strength as high as $10,000 \mathrm{psi}^{2}(703 \mathrm{~kg} /$ $\mathrm{sq} \mathrm{cm}$ ), this is still below the $12,000 \mathrm{psi}$ $(844 \mathrm{~kg} / \mathrm{sq} \mathrm{cm})$ minimum set by the ADA specification. ${ }^{3}$ Horn $^{4}$ reported a clinical study of a zinc oxide-eugenol cement of compressive strength of $10,000 \mathrm{psi}(844 \mathrm{~kg} /$ $\mathrm{sq} \mathrm{cm}$ ) used over a two-year period in

This investigation was supported by a General Research Grant of the School of Dentistry, University of Michigan, Ann Arbor, Mich.

Received for publication November 8, 1968. which restorations of good retentive quality were selected and cemented. No determination has ever been made of the minimum compressive strength that is required for a luting cement. Experience gained in earlier studies ${ }^{5}$ of a cement of $5,400 \mathrm{psi}$ $(380 \mathrm{~kg} / \mathrm{sq} \mathrm{cm}$ ) raised the question as to whether this compressive strength might be adequate. An experimental cement* of compressive strength in the region 8,000 psi $(562 \mathrm{~kg} / \mathrm{sq} \mathrm{cm})$ to $9,200 \mathrm{psi}(647 \mathrm{~kg} /$ sq $\mathrm{cm}$ ) seemed even more favorable for clinical trial. A preliminary study was designed and begun.

\section{Materials and Methods}

A powder-liquid type of zinc oxideeugenol cement was used. The powder was provided in glass vials each containing $0.9 \mathrm{gm}$. The liquid was dispensed from a dropper. The powder-liquid ratio used was $0.9 \mathrm{gm}$ powder to 16 drops (approximately $0.37 \mathrm{ml}$ ) of liquid which produced a cement of film thickness, 20 micrometers ( $u \mathrm{~m})$, and a compressive strength of 8,000 psi $(562 \mathrm{~kg} / \mathrm{sq} \mathrm{cm})$ when set.

The cement was mixed on a parchmenttype paper pad. All the powder was brought into the liquid at once and the mass was repeatedly pressed with a spatula until all the powder was moistened. The moist mass was spatulated rapidly and the mix was completed in 30 to 45 seconds. All types of restorations were cemented; the only criterion used in selecting patients was availability for recall for a minimum period of two years.

The mouth was prepared by inserting a saliva ejector and cotton rolls, and by thoroughly drying the teeth and adjacent tissues with cotton. The abutment teeth were finally dried with cotton and warm air. No

\footnotetext{
* L. D. Caulk Co., Milford, Del.
} 
varnish was applied to the abutments and local anesthesia was not routinely used. The retainers were copiously filled with the cement. Care was exercised to assure that all cavosurfaces of the retainers were wet. The restoration was then carried to place and seated completely by one of the usual technics. At the time the restoration was cemented, note was made of the location of the restoration, the number and type of the retainers and pontics, and the type of connectors. The retentive quality of the retainers and the nature of the occlusion were recorded, and will be reported at a later date. Any comments about the cement by the operator or patient were also recorded.

The patients were systematically recalled for examination of the restorations for evidence of loosened retainers. Excess saliva was cleaned from the restorations with an air syringe and each retainer was subjected in turn to alternate forces of traction and seating pressure in the line of draw of the restoration. A loose retainer was detected by the movement of residual saliva at the gold-tooth interface at the margins of the retainer. The traction pressure of approximately eight pounds was applied with a burnisher* or B scaler.* Seating pressure was applied by having the patient bite firmly on a one-fourth-inch diameter orangewood stick.

The data collected at cementation and recall were transferred to IBM cards and analyzed to prepare a table.

Restorations included in the study were single inlays and crowns, rigid splints of two or three teeth, and fixed, semifixed and cantilever bridges. The bridges ranged from 2 to 14 units that involved from one to seven retainers. The number of spans per bridge ranged from one to three and the span length varied from one to four pontics. Several of the single inlays and crowns, two-unit splints, and bridges of various lengths, supported removable dentures attached by precision attachments, semiprecision attachments, or clasps. All grades of retention and occlusion were represented in the restorations.

A total of 203 cemented restorations were included in the study, consisting of

* S. S. White Co., Pittsburgh, Pa.
620 units of inlay and crown or bridge work or both involving 397 teeth. All restorations were completely seated without difficulty.

\section{Results}

A remarkable absence of pain at cementation was noted. Numerous cementations were made on hypersensitive teeth and no discomfort was experienced by the patient. Although some discomfort was experienced during the period before cementation when the abutments were isolated, relief was immediate when the restoration was seated with the cement.

Three exceptions occurred in regard to the incidence of pain, all of which were related to the cementation of pinledge restorations. In two instances, transient pain was experienced which subsided rapidly once the restoration was completely seated. In the third instance acute pain occurred at the time of cementation and persisted. Subsequent endodontic treatment of this tooth was necessary.

Restorations were in the mouth for varying periods after cementation, from as long as $\mathbf{2 6}$ months for those cemented at the beginning of the study, to as short as one month for those cemented toward the end of the study. Restorations came loose after a time interval as short as nine days, and after a period as long as 22 months. The greater number of failures occurred in the first 11 months with the average failure occurring at 9.5 months.

The data regarding the retention of inlays and crowns are shown in Table 1; data regarding the retention of bridge retainers are shown in Table 2.

\section{Discussion}

The flow qualities of the cement as observed clinically are different from those of the zinc phosphate cements. Restorations appear to seat completely with greater ease.

The absence of pain at cementation and the sedative effect are great advantages in comparison to the irritant nature of the

TABLE 1

Retention of Single INLAys and Crowns

\begin{tabular}{ccc}
\hline No. Cemented & No. Came Loose & Failure (\%) \\
\hline 53 & 3 & 5.6 \\
\hline
\end{tabular}


TABLE 2

RETENTION OF BRDGe ReTAiners

\begin{tabular}{|c|c|c|c|c|c|}
\hline $\begin{array}{c}\text { No. } \\
\text { Restorations } \\
\text { Cemented }\end{array}$ & $\begin{array}{c}\text { Units per } \\
\text { Restoration }\end{array}$ & $\begin{array}{c}\text { Retainers } \\
\text { per } \\
\text { Restoration }\end{array}$ & $\begin{array}{l}\text { Retainers } \\
\text { Tested }\end{array}$ & $\begin{array}{l}\text { Retainers } \\
\text { Loose }\end{array}$ & $\begin{array}{c}\text { Retainers } \\
\text { Loose (\%) }\end{array}$ \\
\hline 3 & $1 *$ & $1 *$ & 3 & 0 & 0 \\
\hline 1 & $1 \dagger$ & $1^{*}$ & 1 & 0 & 0 \\
\hline 5 & 27 & $1 *$ & 5 & 1 & 20 \\
\hline 1 & 2 & 02 & 2 & 0 & 0 \\
\hline 2 & 3 & $2^{*}$ & 4 & 0 & 0 \\
\hline 85 & 3 & 02 & 170 & 12 & 7.0 \\
\hline 0 & 3 & 03 & $\ldots$ & $\ldots$ & $\ldots$ \\
\hline 1 & $4 \dagger$ & $2^{*}$ & 2 & 0 & 0 \\
\hline 13 & 4 & 02 & 26 & 1 & 3.8 \\
\hline 12 & 4 & 03 & 36 & 0 & 0 \\
\hline 3 & 5 & 02 & 6 & 0 & 0 \\
\hline 9 & 5 & 03 & 27 & 3 & 11.1 \\
\hline 3 & 6 & 02 & 6 & 2 & 33.3 \\
\hline 1 & 6 & 03 & 3 & 0 & 0 \\
\hline 1 & 6 & 04 & 4 & 1 & 25 \\
\hline 0 & 6 & 05 & $\ldots$ & $\ldots$ & $\ldots$ \\
\hline 0 & 7 & 04 & $\ldots$ & $\ldots$ & $\ldots$ \\
\hline 1 & 8 & 03 & 3 & 1 & 33.3 \\
\hline 1 & 8 & $4^{*}$ & 4 & 0 & 0 \\
\hline 2 & 8 & 04 & 8 & 0 & 0 \\
\hline 1 & 9 & 04 & 4 & 0 & 0 \\
\hline 1 & 11 & 05 & 5 & $1 \S$ & 20 \\
\hline 0 & 11 & 06 & $\ldots$ & $\ldots$ & $\ldots$ \\
\hline 1 & 12 & 06 & 6 & 0 & 0 \\
\hline 1 & 13 & 07 & 7 & 0 & 0 \\
\hline 1 & 14 & 05 & 5 & 0 & 0 \\
\hline 1 & 14 & 07 & 7 & 0 & 0 \\
\hline 150 & & & 344 & 22 & 6.4 \\
\hline
\end{tabular}

zinc phosphate cements. In the two instances in which transient pain was experienced at cementation, hydraulic pressure was probably produced on the pulp through the dentin as the pins went to place. In the instance in which acute pain occurred and persisted and endodontic treatment was required, a minute undetectable pulp exposure by the pin preparation is assumed to have inadvertently occurred.

Examining the success obtained $(94.4 \%$ for single restorations and $93.6 \%$ for bridge retainers), it appears justifiable to explore clinical application further. The success rate could undoubtedly be improved by more careful development of retention form in the retainers. In a large undergraduate clinic in which many bridges are made as a first experience, a small failure rate is to be expected. A similar experience is found with the zinc phosphate cements, although documented figures are not available at the time of writing.

\section{Conclusions}

The cements were nonirritating to freshly cut dentin and showed a sedative effect on sensitive abutments. The number of restorations that came loose was not high enough to preclude the use of the cement in further studies. A long-term comparative study of randomly assigned cementations with this experimental zinc oxide-eugenol cement and zine phosphate cement is justified.

\section{References}

1. Gilson, T.D., and Myers, G.E.: Clinical Studies of Dental Cements: III. A Study 
of Seven Zinc Oxide-Eugenol Cements Used for Temporarily Cementing Completed Restorations, J Dent Res 49:14-20, 1970.

2. Civjan, S., and Brauer, G.M.: Physical Properties of Cements Based on Zinc Oxide, Hydrogenated Rosin, O-ethoxybenzoic Acid and Eugenol, $J$ Dent Res 43:281$300,1964$.

3. American Dental Association Specification No. 8, Guide To Dental Materials, 3rd ed,
Chicago: American Dental Association, 1966.

4. HoRN, H.R.: The Cementation of Crowns and Fixed Partial Dentures," in Dental Clinics Of North America, Philadelphia: W. B. Saunders Co., 1965, pp 65-81.

5. GILson, T.D., and MYers, G.E.: Clinical Studies of Dental Cements:I. A Preliminary Study of Five Zinc Oxide-Eugenol Cements, J Dent Res 47:737-742, 1968. 